\title{
Assessing the Impact of Vessel Centering on Dissolution Results-A Case Study
}

Jian-Hwa Han ${ }^{1,}{ }^{*}$, Anagha Vaidya ${ }^{2}$, Daniel Bonilla ${ }^{1}$, and Stephen Anderson ${ }^{1}$

${ }^{1}$ NCE Analytical R\&D, AbbVie Inc, 1 North Waukegan Road, North Chicago, IL 60064

${ }^{2}$ Formulation R\&D, Teva Pharmaceuticals, 1090 Horsham Road, North Wales, PA 19454

e-mail: jian-hwa.h.han@abbvie.com

\begin{abstract}
Vessel-centering determination carried out as a part of Enhanced Mechanical Calibration is the most sensitive parameter to vessel inconsistencies and therefore tightly controlled. The FDA/ASTM criterion for vessel centering is $1.0 \mathrm{~mm}$. However, the impact of off-centered vessels on drug release and dissolution has not been evaluated. We attempted to design a practical approach to evaluate a critical tolerance range around the acceptance criteria. Experiments were conducted by manually adjusting vessels to varying degrees of off-center. Dissolution testing was carried out using USP Prednisone Tablets RS, and the geometric mean and \%CV were calculated using the PVT calculation tool and template and assigned pass/fail criteria based on the USP acceptance criteria. The test results passed Stage 1 at nominal and $\approx 1.0-\mathrm{mm}$ centering conditions and passed the $\approx 1.5-\mathrm{mm}$ condition at Stage 2 . The PVT results failed at $\approx 2.0-\mathrm{mm}$ centering condition. The data indicate that a stricter alignment practice might be necessary during calibration and routine use to ensure vessel centering is maintained per the FDA criteria. An ad hoc policy allowing no investigation for centering values greater than $1.0 \mathrm{~mm}$ but less than $1.5 \mathrm{~mm}$ during calibration might be suitable for routine maintenance of dissolution Apparatus 1 and 2.
\end{abstract}

KEYWORDS: Dissolution; vessel centering; enhanced mechanical calibration; FDA; ASTM; prednisone tablets; USP; PVT; acceptance criteria.

\section{INTRODUCTION}

SP Performance Verification Tests (PVTs) have served as the industry standard for the performance check of USP dissolution Apparatus 1 and 2 (1). FDA has published guidance for enhanced mechanical calibration (EMC) of dissolution apparatus (2) that can be utilized alternatively to calibrate the dissolution apparatus to similar standards but without the need to perform dissolution testing with reference prednisone tablets. Because the EMC does not include PVT using USP Prednisone Tablets RS, it requires additional checks and stricter criteria for some parameters (e.g., two-point vessel-centering check with acceptance criterion of $1.0 \mathrm{~mm}$ ) (3-5). All dissolution testing laboratories are mandated by FDA to calibrate and qualify the apparatus based on a standardized written procedure. Most laboratories follow either USP PVT or EMC, or a combination of both.

In our laboratory, USP Apparatus 1 and 2 are maintained through Enhanced Mechanical Calibration per current FDA/ASTM standards $(3,4)$. The instrument calibration includes checks for basket and paddle height, rotational speed, shaft wobble, shaft verticality, basket wobble, vessel/shaft centering measured at two positions, vessel

\footnotetext{
*Corresponding author.
}

verticality, and vessel plate level. Of these instrument parameters, vessel/shaft centering is one of the most sensitive to vessel variability and is tightly controlled. Although there have been studies to evaluate the effect of apparatus variables on drug release (6-10), the impact specifically related to different centering values on dissolution results is still unknown. To evaluate the critical tolerance range around the ASTM centering value of $1.0 \mathrm{~mm}$ and the impact of off-centered vessels on drug release, experiments were carried out by manually adjusting the vessels to various off-centered conditions that were confirmed with an Agilent Q280 Mechanical Qualification System. Dissolution testing was performed in well-centered vessels and in vessels with centering values around $1.0 \mathrm{~mm}, 1.5 \mathrm{~mm}$, and $2.0 \mathrm{~mm}$ using prednisone 10-mg tablets. Data were analyzed in two ways based on the tablet source:

1. USP Prednisone Tablets RS: The PVT Calculation Tool V2.0 (11) and Calculation Template from the USP Web site was used to determine the geometric mean (GM) and coefficient of variation (\%CV). Data were assigned pass/ fail criteria per USP recommendations (12-14).

2. FDA Prednisone Tablets: Because there is no calculation template or predetermined criteria assigned, Minitab software was used for statistical analysis (15). 


\section{EXPERIMENTAL APPARATUS, MATERIALS,}

\section{AND METHODS}

\section{Apparatus}

Dissolution testing was carried out in an Agilent 7010 dissolution apparatus with paddles. The TruCenter vessels from Agilent were used to minimize the impact from vessel shape. The apparatus was qualified in-house by our Calibration Metrology Group using a calibrated QA station (Agilent Technologies, Santa Clara, CA) and maintained per FDA/ASTM standards. Vessel-centering and verticality values were obtained using a calibrated Agilent 280-DS Mechanical Qualification System (SVM, Serial number US12380848; IM, Serial number US12380849). A custommade plastic disc (spacer) of defined thickness was used to adjust the vessels to off-center conditions (Figure 1). The off-center effect was achieved by tilting the vessel. Dissolution data were acquired using a UV-vis fiber-optic dissolution testing system (Distek, Inc., North Brunswick, NJ).

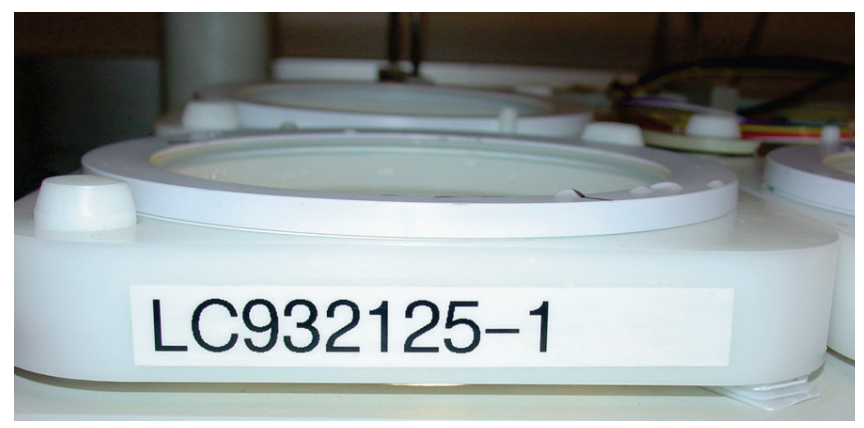

Figure 1. Artificial off-centering achieved by adding spacers at the vessel base. Different numbers of plastic spacers were inserted under the right-hand corner to achieve the desired level of off-center values.

\section{Materials}

USP Prednisone Tablets RS (Lot QOH398) were purchased from the USP reference catalog. The acceptance criteria for Lot Q0H398 are listed in Table 1. In addition, 10-mg Prednisone Dissolution Test Performance Standard Tablets (Lot: NCDA \#2) were obtained from FDA for comparison.

Table 1. GM and \%CV Acceptance Criteria for USP Prednisone Tablets RS, Lot QOH398, for Stage 1 and Stage 2 Dissolution Test for USP Apparatus with Six Positions

\begin{tabular}{|r|c|c|}
\hline & Stage 1 & Stage 2 \\
\hline GeoMean, lower & 27 & 26 \\
\hline GeoMean, upper & 36 & 38 \\
\hline \%CV, upper & 4.9 & 6.5 \\
\hline
\end{tabular}

\section{Methods}

Dissolution testing was carried out in $500 \mathrm{~mL}$ of deaerated, deionized water obtained in-house. The USP tablet release data were calculated per USP guidance using the USP Toolkit for calculation to get the pass/ fail assessment. The release data for FDA tablets were analyzed with Minitab software.

\section{STUDY DESIGN AND PROCEDURES}

The study design for the vessel-centering evaluation was based on the typical bath setup and daily operation of our labs. It is as below.

1. Before each experiment, the shaft verticality and vessel-centering values at lower and upper positions along with all other parameters (e.g., paddle height, shaft wobble, and rotation speed) were measured with the Agilent 280-DS MQS. For a calibrated bath, all conditions remained the same, except for the intended variations in vessel centering achieved by tilting the vessel, in which case an inherent impact to vessel verticality is expected.

2. For Agilent 7010 systems, the dissolution vessel can be adjusted to four different positions determined by the magnetic locking mechanism. Vessel-centering values were obtained for all four positions, and the position that provided the suitable centering value was used.

3. The vessel-centering values were adjusted so as to be within the desirable range of the designed experiment: Good Centering (as small a value as possible), Borderline $(\approx 1.0 \mathrm{~mm})$, Off-centered $(\approx 1.5 \mathrm{~mm})$, and Extremely Off-centered $(\approx 2.0 \mathrm{~mm})$. The individual centering and verticality values are listed in Tables 2 and 3 (next page). The lower centering value is the parameter most affected.

4. The nominal centering position with mean lower centering values of 0.4 and $0.5 \mathrm{~mm}$ was used as the reference point.

5. Vessels were adjusted to off-center using the plastic disc spacer, and three levels were achieved.

- Borderline centering $(\approx 1.0 \mathrm{~mm})$

- Off-centered ( $\approx 1.5 \mathrm{~mm})$

- Extremely off-centered $(\approx 2.0 \mathrm{~mm})$

6. Dissolution testing was carried out at each condition mentioned above. At least six tablets were used at each centering condition. Experiments were carried out with both FDA and USP tablets.

7. Data were acquired with the FO testing system using Distek Arch probes with a $10-\mathrm{mm}$ path length and from 
Table 2. Vessel-Centering and Verticality Values for USP Prednisone Runs

\begin{tabular}{|c|c|c|c|c|c|c|c|}
\hline \multirow{2}{*}{$\begin{array}{c}\text { USP Tablet } \\
\text { Normal }\end{array}$} & \multicolumn{4}{|c|}{ Vessel Centering $(\leq 1.0 \mathrm{~mm})$} & \multicolumn{3}{|c|}{ Vessel Verticality $\left(\leq 1.0^{\circ}\right)$} \\
\hline & Lower & Pass/Fail & Upper & Pass/Fail & pt1 & pt2 & Pass/Fail \\
\hline Vessel 1 & 0.1 & Pass & 0.2 & Pass & 0.4 & -0.1 & Pass \\
\hline Vessel 2 & 0.6 & Pass & 0.2 & Pass & 0.2 & -0.3 & Pass \\
\hline Vessel 3 & 0.7 & Pass & 0.4 & Pass & 0.5 & -0.2 & Pass \\
\hline Vessel 4 & 0.8 & Pass & 0.3 & Pass & 0.0 & -0.3 & Pass \\
\hline Vessel 5 & 0.4 & Pass & 0.3 & Pass & 0.2 & -0.1 & Pass \\
\hline Vessel 6 & 0.3 & Pass & 0.6 & Pass & 0.3 & 0.1 & Pass \\
\hline Borderline & Lower & Pass/Fail & Upper & Pass/Fail & pt1 & pt2 & Pass/Fail \\
\hline Vessel 1 & 1.1 & Fail & 0.3 & Pass & 0.0 & -0.8 & Pass \\
\hline Vessel 2 & 1.0 & Pass & 0.4 & Pass & 0.3 & -0.7 & Pass \\
\hline Vessel 3 & 1.1 & Fail & 0.5 & Pass & 0.5 & -0.5 & Pass \\
\hline Vessel 4 & 1.2 & Fail & 0.7 & Pass & 0.4 & -0.7 & Pass \\
\hline Vessel 5 & 1.0 & Pass & 0.4 & Pass & -0.1 & 0.2 & Pass \\
\hline Vessel 6 & 1.0 & Pass & 0.8 & Pass & 0.9 & -0.1 & Pass \\
\hline$\approx 1.5 \mathrm{~mm}^{a}$ & Lower & Pass/Fail & Upper & Pass/Fail & pt1 & pt2 & Pass/Fail \\
\hline Vessel 1 & 1.6 & Fail & 0.3 & Pass & -0.1 & -1.1 & Fail \\
\hline Vessel 2 & 1.4 & Fail & 0.5 & Pass & 1.0 & -0.7 & Pass \\
\hline Vessel 3 & 1.5 & Fail & 0.7 & Pass & 0.1 & -0.7 & Pass \\
\hline Vessel 4 & 1.5 & Fail & 0.5 & Pass & 0.2 & -0.9 & Pass \\
\hline Vessel 5 & 1.7 & Fail & 0.2 & Pass & -1.0 & -0.1 & Pass \\
\hline Vessel 6 & 1.5 & Fail & 0.4 & Pass & 0.1 & -1.0 & Pass \\
\hline$\approx 2.0 \mathrm{~mm}^{a}$ & Lower & Pass/Fail & Upper & Pass/Fail & pt1 & pt2 & Pass/Fail \\
\hline Vessel 1 & 1.9 & Fail & 0.4 & Pass & 0.1 & -1.3 & Fail \\
\hline Vessel 2 & 1.9 & Fail & 0.4 & Pass & 0.9 & -1.2 & Fail \\
\hline Vessel 3 & 2.1 & Fail & 0.7 & Pass & 0.2 & -1.2 & Fail \\
\hline Vessel 4 & 2.0 & Fail & 0.8 & Pass & 1.0 & -0.7 & Pass \\
\hline Vessel 5 & 2.0 & Fail & 0.3 & Pass & -1.1 & 0.3 & Fail \\
\hline Vessel 6 & 2.2 & Fail & 0.5 & Pass & -0.3 & -1.5 & Fail \\
\hline Nominal $^{b}$ & Lower & Pass/Fail & Upper & Pass/Fail & pt1 & pt2 & Pass/Fail \\
\hline Vessel 1 & 0.0 & Pass & 0.2 & Pass & 0.3 & -0.1 & Pass \\
\hline Vessel 2 & 0.6 & Pass & 0.1 & Pass & -0.1 & -0.4 & Pass \\
\hline Vessel 3 & 0.3 & Pass & 0.4 & Pass & 0.0 & -0.3 & Pass \\
\hline Vessel 4 & 0.7 & Pass & 0.1 & Pass & -0.1 & -0.4 & Pass \\
\hline Vessel 5 & 0.2 & Pass & 0.1 & Pass & 0.1 & -0.2 & Pass \\
\hline Vessel 6 & 0.3 & Pass & 0.2 & Pass & 0.0 & -0.1 & Pass \\
\hline
\end{tabular}

${ }^{a} n=12$ testing performed. $\quad{ }^{b}$ Confirmation run to show the impact is reversible.

an average of 5 scans. The detection wavelength was set to $242 \mathrm{~nm}$, and a baseline correction from 360 to $375 \mathrm{~nm}$ was applied to absorbance data.

8. Standard solutions were prepared using a prednisone reference standard, and absorbance values were obtained for the standards using the same instrument settings as those used for the samples.

9. At the beginning of the run, the probes were placed in dissolution vessels containing the media, a sample blank was acquired, tablets were added to the vessels, and the dissolution run was started with an agitation rate of $50 \mathrm{rpm}$. Data were collected every minute for $60 \mathrm{~min}$ followed by data collection for full recovery at $200 \mathrm{rpm}$ every minute for another $30 \mathrm{~min}$. See Figure 2 for the typical dissolution profiles of USP Prednisone Tablets RS.

10. The data analysis was performed using USP PVT Calculation Tool V2.0 and Minitab software, Version 16. 
Table 3. Vessel-Centering and Verticality Values for FDA Prednisone Runs

\begin{tabular}{|c|c|c|c|c|c|c|c|}
\hline \multirow{2}{*}{$\begin{array}{c}\text { USP Tablet } \\
\text { Normal }\end{array}$} & \multicolumn{4}{|c|}{ Vessel Centering $(\leq 1.0 \mathrm{~mm})$} & \multicolumn{3}{|c|}{ Vessel Verticality $\left(\leq 1.0^{\circ}\right)$} \\
\hline & Lower & Pass/Fail & Upper & Pass/Fail & pt1 & pt2 & Pass/Fail \\
\hline Vessel 1 & 0.0 & Pass & 0.2 & Pass & 0.3 & -0.1 & Pass \\
\hline Vessel 2 & 0.4 & Pass & 0.2 & Pass & 0.2 & -0.3 & Pass \\
\hline Vessel 3 & 0.5 & Pass & 0.3 & Pass & 0.4 & -0.3 & Pass \\
\hline Vessel 4 & 0.7 & Pass & 0.2 & Pass & -0.1 & -0.5 & Pass \\
\hline Vessel 5 & 0.2 & Pass & 0.1 & Pass & 0.1 & -0.1 & Pass \\
\hline Vessel 6 & 0.6 & Pass & 0.7 & Pass & 0.3 & 0.0 & Pass \\
\hline Nominal $^{a}$ & Lower & Pass/Fail & Upper & Pass/Fail & pt1 & pt2 & Pass/Fail \\
\hline Vessel 1 & 0.3 & Pass & 0.1 & Pass & 0.2 & -0.4 & Pass \\
\hline Vessel 2 & 0.4 & Pass & 0.2 & Pass & 0.2 & -0.3 & Pass \\
\hline Vessel 3 & 0.6 & Pass & 0.4 & Pass & 0.4 & -0.3 & Pass \\
\hline Vessel 4 & 0.4 & Pass & 0.1 & Pass & 0.0 & -0.4 & Pass \\
\hline Vessel 5 & 0.3 & Pass & 0.1 & Pass & 0.1 & -0.2 & Pass \\
\hline Vessel 6 & 0.5 & Pass & 0.6 & Pass & 0.4 & 0.1 & Pass \\
\hline Borderline & Lower & Pass/Fail & Upper & Pass/Fail & pt1 & pt2 & Pass/Fail \\
\hline Vessel 1 & 1.1 & Fail & 0.4 & Pass & -0.2 & -0.8 & Pass \\
\hline Vessel 2 & 0.9 & Pass & 0.5 & Pass & 0.0 & -0.4 & Pass \\
\hline Vessel 3 & 1.0 & Pass & 0.6 & Pass & 0.3 & -0.6 & Pass \\
\hline Vessel 4 & 1.3 & Fail & 0.9 & Pass & 0.5 & -0.6 & Pass \\
\hline Vessel 5 & 0.9 & Pass & 0.5 & Pass & -0.1 & 0.1 & Pass \\
\hline Vessel 6 & 0.9 & Pass & 0.9 & Pass & 0.8 & 0.0 & Pass \\
\hline Borderline $^{a}$ & Lower & Pass/Fail & Upper & Pass/Fail & pt1 & pt2 & Pass/Fail \\
\hline Vessel 1 & 1.1 & Fail & 0.4 & Pass & 0.0 & -0.9 & Pass \\
\hline Vessel 2 & 1.1 & Fail & 0.6 & Pass & 0.3 & -0.5 & Pass \\
\hline Vessel 3 & 1.1 & Fail & 0.7 & Pass & 0.2 & -0.6 & Pass \\
\hline Vessel 4 & 1.3 & Fail & 0.9 & Pass & 0.5 & -0.6 & Pass \\
\hline Vessel 5 & 0.9 & Pass & 0.5 & Pass & -0.2 & 0.4 & Pass \\
\hline Vessel 6 & 1.2 & Fail & 0.9 & Pass & 0.9 & -0.2 & Pass \\
\hline$\approx 1.5 \mathrm{~mm}$ & Lower & Pass/Fail & Upper & Pass/Fail & pt1 & pt2 & Pass/Fail \\
\hline Vessel 1 & 1.5 & Fail & 0.4 & Pass & -0.1 & -1.1 & Fail \\
\hline Vessel 2 & 1.4 & Fail & 0.3 & Pass & 0.8 & -0.8 & Pass \\
\hline Vessel 3 & 1.5 & Fail & 0.8 & Pass & 0.2 & -0.7 & Pass \\
\hline Vessel 4 & 1.5 & Fail & 0.5 & Pass & 0.2 & -0.9 & Pass \\
\hline Vessel 5 & 1.7 & Fail & 0.5 & Pass & -0.7 & 0.1 & Pass \\
\hline Vessel 6 & 1.7 & Fail & 0.5 & Pass & 0.3 & -1.1 & Fail \\
\hline$\approx 2.0 \mathrm{~mm}$ & Lower & Pass/Fail & Upper & Pass/Fail & pt1 & pt2 & Pass/Fail \\
\hline Vessel 1 & 1.9 & Fail & 0.4 & Pass & -0.1 & -1.4 & Fail \\
\hline Vessel 2 & 1.9 & Fail & 0.3 & Pass & 0.6 & -1.4 & Fail \\
\hline Vessel 3 & 2.1 & Fail & 0.7 & Pass & 0.3 & -1.2 & Fail \\
\hline Vessel 4 & 2.0 & Fail & 0.8 & Pass & 1.0 & -0.6 & Pass \\
\hline Vessel 5 & 2.0 & Fail & 0.4 & Pass & -1.0 & 0.4 & Pass \\
\hline Vessel 6 & 2.1 & Fail & 0.4 & Pass & -0.2 & -1.4 & Fail \\
\hline
\end{tabular}

${ }^{a}$ Replicate experiment to confirm the observation. 


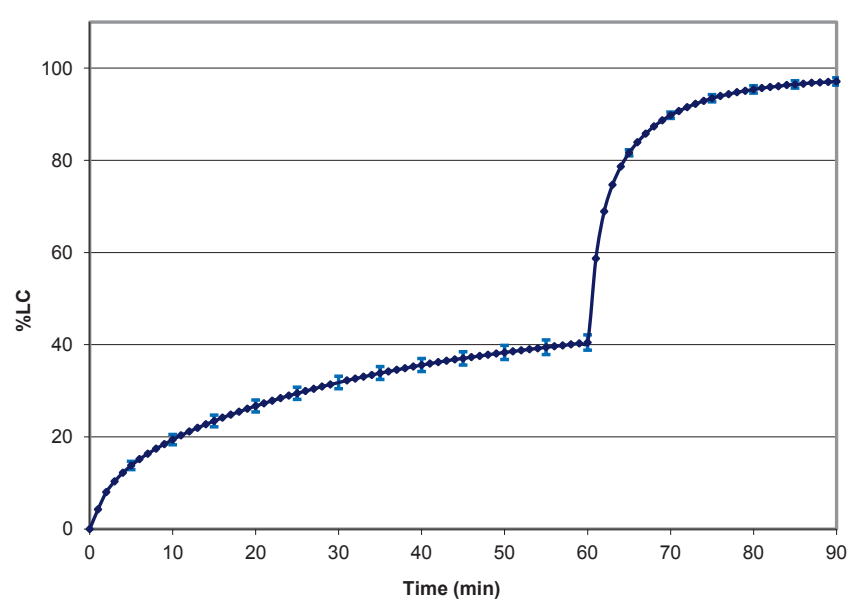

Figure 2. A typical dissolution profile of USP Prednisone Tablets Reference Standard: dissolution at $50 \mathrm{rpm}$ for $60 \mathrm{~min}$; full release achieved at $200 \mathrm{rpm}$ after $60 \mathrm{~min}$. (\%LC = \%Dissolved.)

\section{RESULTS}

\section{USP Prednisone Tablets RS}

The USP Prednisone Tablets RS is recommended by USP for use in the Performance Verification Test of a Dissolution Apparatus (i.e., Apparatus 1 - basket or Apparatus 2 - paddle). The acceptance criteria for PVT Tablets RS are established through statistical evaluations of data from a multi-lab collaborative study (12-14). The acceptance criteria for Lot $\mathrm{Q} 0 \mathrm{H} 398$ are shown in Table 1.

The experimental progression is from the nominal position $(<1.0 \mathrm{~mm})$ to borderline $(\approx 1.0 \mathrm{~mm})$, off-center $(\approx 1.5 \mathrm{~mm})$, and the extreme $(\approx 2.0 \mathrm{~mm})$. The calculated $\mathrm{GM}$ and \%CV values for all vessels at each centering condition are shown in Table 4. Individual \%LC data for the USP Prednisone Tablets RS were plotted against the centering value with color coded data sets reflecting different centering conditions (Figure 3). All tested samples passed the Stage 1 test at the nominal and borderline centering conditions. At the $\approx 1.5-\mathrm{mm}$ offcentered condition, the $\mathrm{GM}$ passed and $\% \mathrm{CV}$ value failed at Stage 1; however, both the GM and the \%CV passed at Stage 2 . When the vessel-centering values were adjusted at or above $2.0 \mathrm{~mm}$, the dissolution results failed the PVT test $(n=12)$ requirements for $G M$ and $\% C V$ at Stage 1 and failed \%CV at Stage 2. This indicates the bath is not suitable to generate quality data consistently at the extreme off-centered position. At the end of the study, the vessels were readjusted to the nominal position, and the PVT test was repeated. The results passed the PVT acceptance criteria, confirming that the impact from vessel off-centering is reversible.

Prednisone Tablet - USP Ref Std.

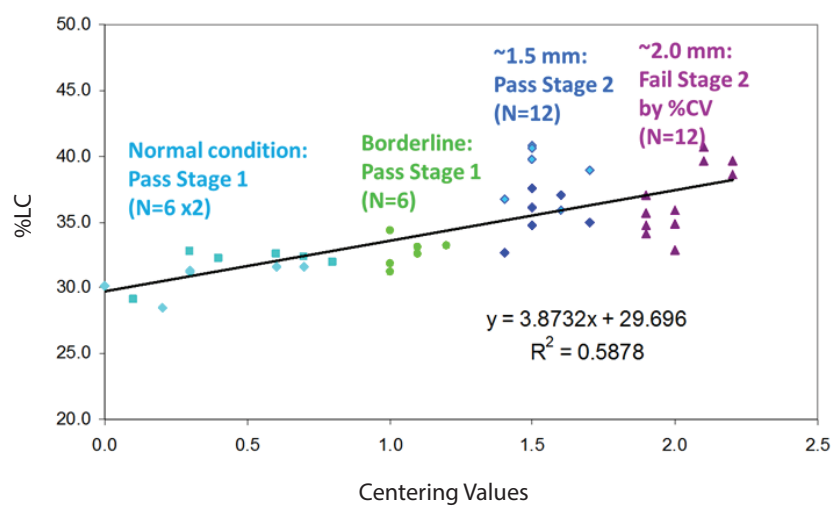

Figure 3. Percentage dissolved at $30 \mathrm{~min}(\% \mathrm{LC})$ data trending from the USP Prednisone Tablets RS at different centering conditions.

Table 4. PVT Results from Dissolution Testing of USP Tablets RS at Different Vessel-Centering Conditions

\begin{tabular}{|c|c|c|c|c|c|c|c|c|c|}
\hline Run ID & Stage & 1 & 2 & 3 & 4 & 5 & 6 & GeoMean & $\% \mathrm{CV}$ \\
\hline Nominal & Stage 1 & 29.1 & 32.5 & 32.3 & 31.9 & 32.2 & 32.8 & 32 & 4.4 \\
\hline \multicolumn{7}{|c|}{ (Lower Center: Mean $=0.5 ; \mathrm{SD}=0.26$ ) } & Result: & \multicolumn{2}{|c|}{ Passes } \\
\hline Borderline & Stage 1 & 33.1 & 31.8 & 32.5 & 33.2 & 31.2 & 34.3 & 33 & 3.4 \\
\hline \multicolumn{7}{|c|}{ (Lower Center: Mean $=1.1 ;$ SD $=0.08$ ) } & Result: & \multicolumn{2}{|c|}{ Passes } \\
\hline \multirow[t]{2}{*}{$\approx 1.5 \mathrm{~mm}$} & Stage 1 & 37 & 32.6 & 34.7 & 37.8 & 34.9 & 36.1 & 35 & $5.2^{a}$ \\
\hline & Stage 2 & 35.9 & 36.7 & 39.8 & 40.8 & 38.9 & 40.6 & 37 & 5.3 \\
\hline \multicolumn{7}{|c|}{ (Lower Center: Mean $=1.5 ;$ SD $=0.10$ ) } & Result: & \multicolumn{2}{|c|}{ Passes (Stage 2) } \\
\hline \multirow[t]{2}{*}{$\approx 2.0 \mathrm{~mm}$} & Stage 1 & 37 & 34.7 & 40.7 & 32.9 & 35.9 & 38.6 & $37^{a}$ & $7.6^{a}$ \\
\hline & Stage 2 & 35.7 & 34.1 & 39.7 & 35.9 & 34.8 & 39.6 & 37 & $7.1^{a}$ \\
\hline \multicolumn{7}{|c|}{ (Lower Center: Mean $=2.0 ;$ SD $=0.12$ ) } & Result: & \multicolumn{2}{|c|}{ Fails } \\
\hline Nominal $^{b}$ & Stage 1 & 30.1 & 31.6 & 31.2 & 31.6 & 28.5 & 31.3 & 31 & 4.1 \\
\hline \multicolumn{7}{|c|}{ (Lower Center: Mean $=0.4 ; S D=0.26$ ) } & Result: & \multicolumn{2}{|c|}{ Passes } \\
\hline
\end{tabular}

${ }^{a}$ Values fail the criteria. $\quad{ }^{b}$ Confirmation run to show the impact is reversible. 


\section{FDA Prednisone Tablet, NCDA \#2}

The FDA's Prednisone tablets have drug release characteristics similar to those of USP Prednisone Tablets RS, but the USP PVT Calculation Tool cannot be used to analyze the pass/fail results. Individual \%LC data for the NCDA \#2 Prednisone Tablet were plotted against the lower centering values with color coded data sets reflecting different centering conditions (Figure 4). A statistical analysis was performed with Minitab software to evaluate the effect of the factor studied (i.e., vessel centering) on the response (i.e., \%LC) with statistical significance $(\alpha)$ set at 0.05 . The $\% \mathrm{LC}$ and $\% \mathrm{RSD}$ results for each centering condition are summarized in Table 5. A Pareto chart of standardized effects is used to determine the magnitude and the importance of an effect.

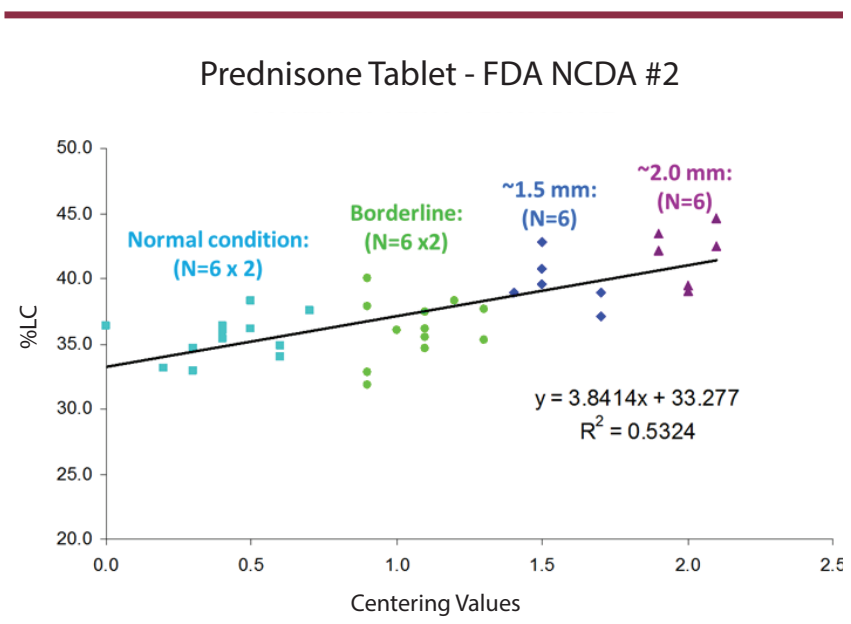

Figure 4. Percentage dissolved at $30 \mathrm{~min}(\% \mathrm{LC})$ data trending from the NCDA \#2 Prednisone Tablet at different centering conditions.

Table 5. \%LC Data Trending from the FDA Prednisone Tablets (NCDA \#2) at Different Centering Conditions ( $n=6$ for each set)

\begin{tabular}{|l|c|c|c|c|c|c|}
\hline $\begin{array}{c}\text { Centering } \\
\text { Condition }\end{array}$ & Run \# & $\begin{array}{c}\text { \%LC } \\
\text { (mean) }\end{array}$ & SD & $\%$ RSD & $\begin{array}{c}\text { Lower } \\
\text { Centering } \\
\text { (mean) }\end{array}$ & SD \\
\hline Normal & $\mathrm{I}$ & 36 & 1.5 & 4.22 & 0.4 & 0.26 \\
\hline Normal & $\mathrm{II}$ & 35 & 1.9 & 5.38 & 0.4 & 0.12 \\
\hline Borderline & $\mathrm{I}$ & 36 & 2.5 & 6.71 & 1.0 & 0.16 \\
\hline Borderline & $\mathrm{II}$ & 36 & 2.4 & 6.78 & 1.1 & 0.13 \\
\hline$\approx 1.5 \mathrm{~mm}$ & $\mathrm{I}$ & 40 & 1.9 & 4.92 & 1.6 & 0.12 \\
\hline$\approx 2.0 \mathrm{~mm}$ & $\mathrm{I}$ & 42 & 2.2 & 5.25 & 2.0 & 0.09 \\
\hline
\end{tabular}

The chart displays the absolute value of the effect and a reference line. Figures 5 and 6 show Pareto charts for standardized effects of the centering values with and without the 2.0-mm condition data set. All data from nominal, borderline, and $\approx 1.5-\mathrm{mm}$ centering positions show that vessel centering did not significantly affect \%LC (Figure 5; the value of bar is below the reference line). The results, including data obtained at $\approx 2.0-\mathrm{mm}$ centering values, show a significant effect on \%LC (Figure 6 ; the value of bar A, centering, is over the reference line). Based on data trending and Pareto charts, centering has a significant effect on \%LC only when beyond the $1.5-\mathrm{mm}$ off-centered condition. This observation agrees with the results from USP Prednisone Tablets RS.

Pareto Chart of the Standardized Effects (response is \%LC, Alpha $=0.05$ )

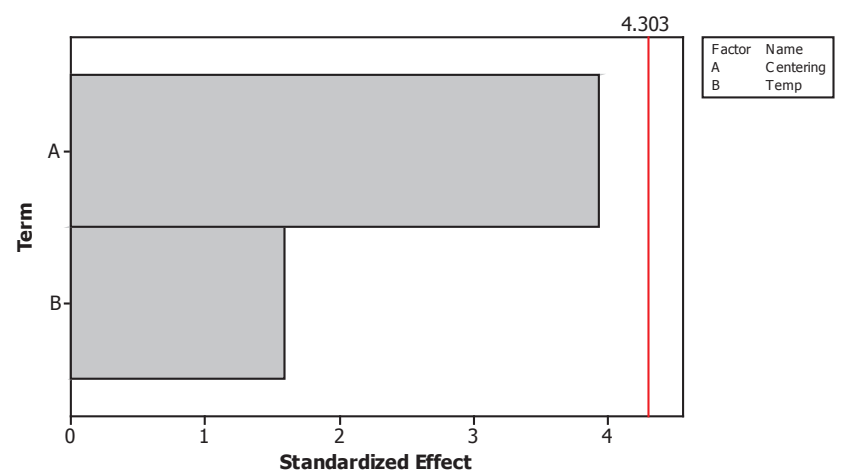

Figure 5. The Pareto chart of the Standardized Effects with data up to $\approx 1.5 \mathrm{~mm}$ centering shows centering and temperature are not significant factors.

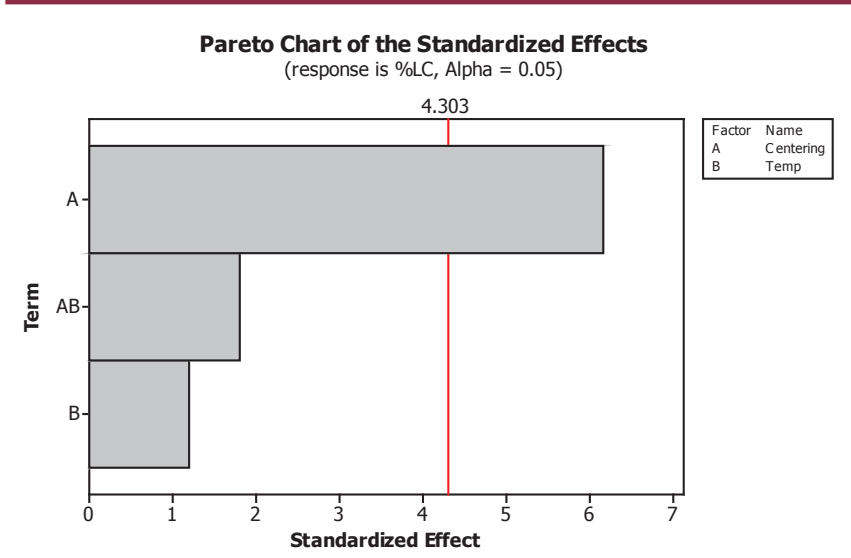

Figure 6. The Pareto Chart of the Standardized Effects with all data including $\approx 2.0 \mathrm{~mm}$ showed centering value has a significant effect on \%LC. The temperature shows no significant impact to $\% L C$.

\section{DISCUSSION}

The experiments quantified the impact of vessel centering on drug release of prednisone tablets. Based on the data, it appears that the centering values less than 1.5 $\mathrm{mm}$ may not significantly affect the dissolution results for prednisone tablets. However, centering positions at $\approx 2.0 \mathrm{~mm}$ affect drug release significantly. (Note: The tilted vessel will also impact the vessel verticality, and it failed the criterion of $>1.0^{\circ}$ only at $\approx 1.5-\mathrm{mm}$ and $\approx 2.0-\mathrm{mm}$ conditions.) 
Vessel centering is the measurement between the vessel wall and the rotating shaft. It is sensitive to vessel shape, geometry, and alignment, and poor centering may impact dissolution data. Thus, conformation of centering to strict criteria is an integral part of dissolution calibration procedure.

Therefore, the best quality vessels are recommended for use in all the dissolution apparatus to minimize centering issues due to vessel shape. In addition, vessel centering can be optimized by identifying the best-fitting orientation in the vessel holder.

A practical approach has been proposed for our routine dissolution bath calibration procedures and daily operation to maintain the vessels per ASTM criteria with centering of $1.0 \mathrm{~mm}$. It suggests that in situations where the centering values of a few vessels obtained during calibration are greater than $1.0 \mathrm{~mm}$ but less than $1.5 \mathrm{~mm}$, all data generated using the instrument/vessel within the calibration window would be deemed acceptable.

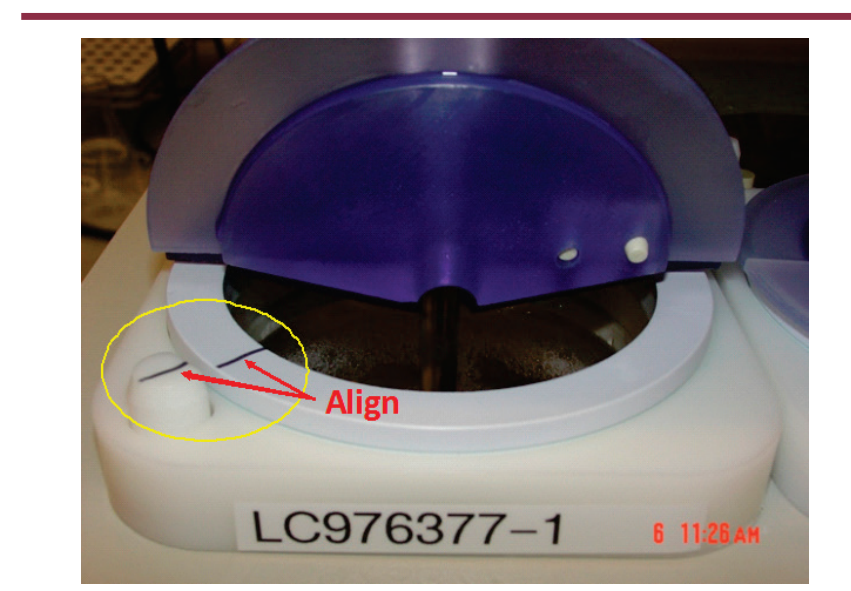

Figure 7. Identification mark for vessel position with lowest centering values in Agilent VK 7000/7010 Dissolution Baths.

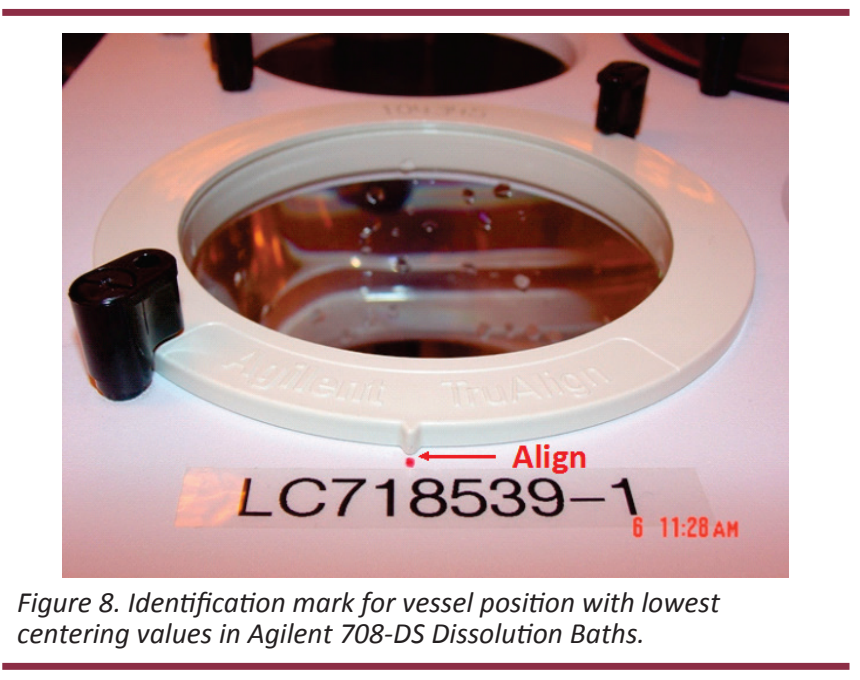

The following suggestions are recommended:

1. During routine calibration, the metrology engineer (who performs the bath calibration) will identify the centering position for each vessel that provides lowest values at both upper and lower measurement positions and make a recognizable mark. See Figure 7 for the example of Agilent VK 7000/7010 and Figure 8 for Agilent 708-DS Dissolution Bath.

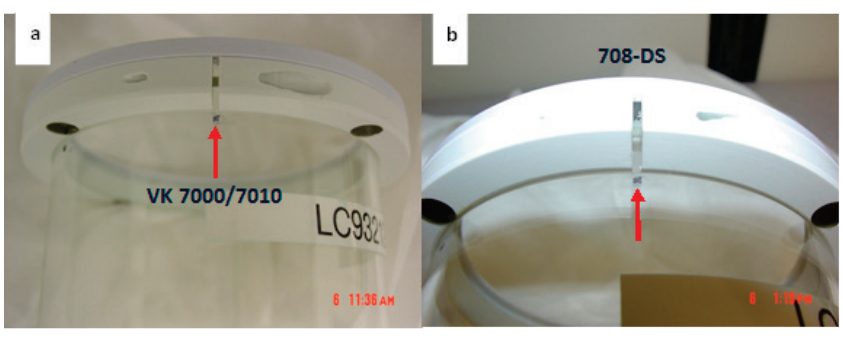

Figure 9. Example for etching an identifying mark for (a) Agilent 7000/7010 and (b) 708-DS Dissolution Vessels.

2. The glass vessel is secured into a ring holder. It has been observed that the glass vessel may rotate around the ring after a warm-water wash in the dishwasher. Therefore, it is important to make sure the vessel and the ring are well aligned. During calibration of a dissolution bath using a new vessel(s), each vessel and its corresponding position with the ring is etched. At each time before use and during calibration, personnel ensure that the vessel and the ring are in the same relative position as defined by the etch mark (Figure 9). The vessel is realigned if necessary.

3. Because the vessel ring and the vessel holder are made from plastic materials, their shapes may change slightly over time. In such cases, if the optimized position is different from the previously established mark, the metrology engineer may re-mark the vessel, the holder, or both during routine calibration to obtain a suitable position with the lowest centering values. Replace the vessel if the centering value cannot be adjusted back to $<1.0 \mathrm{~mm}$.

4. In the unlikely event that during routine calibration an "as found" value of $>1.0 \mathrm{~mm}$ but less than $1.5 \mathrm{~mm}$ is obtained, an investigation may not be necessary for the incident. However, if the mean centering value of $\geq 1.5$ $\mathrm{mm}$ is obtained, a lab investigation will be initiated to determine the impact on the dissolution results.

\section{CONCLUSIONS}

The vessel-centering experiment was designed to obtain a basic understanding of the impact of vessel-centering deviation on drug release. For this purpose, the USP 
Prednisone Tablets RS were used to obtain a tolerance range around the ASTM criteria for centering.

Vessel centering was shown to impact dissolution of prednisone tablets at centering values of $\approx 2.0 \mathrm{~mm}$, but there was no significant impact at the borderline condition (0.9-1.3 mm). Prednisone Tablets RS dissolution carried out in vessels with centering at $\approx 1.5 \mathrm{~mm}$ passed the PVT criteria when calculated per the USP Calculation Tool. These experiments provide a tolerance range for centering slightly over the $1.0-\mathrm{mm}$ specification where dissolution results do not appear to be significantly impacted. A similar finding was obtained for the FDA NCDA \#2 Prednisone Tablets. It is recommended that an alignment practice be added to the calibration protocols and daily practice to ensure centering is maintained. We would still keep the centering criterion at $1.0 \mathrm{~mm}$ per the FDA/ASTM as the highest standard for best practice. This is a more conservative control before the centering effect may impact the dissolution results. In an unlikely event that the centering value of $>1.0 \mathrm{~mm}$ but less than $1.5 \mathrm{~mm}$ is obtained during routine calibration, an investigation may not be necessary for this incident. However, if the mean centering value is $\geq 1.5 \mathrm{~mm}$, a lab investigation will be initiated to determine the impact on the dissolution results.

\section{ACKNOWLEDGMENTS}

The authors thank Dr. Zongming Gao of FDA for providing the NCDA \#2 Prednisone Tablets as well as the technical discussions. We would also like to thank Agilent for lending us the 280-DS Mechanical Calibration System to check the calibration parameters for each experimental run.

\section{DISCLOSURE}

This study was funded by AbbVie. AbbVie participated in the study design, research, data collection, analysis, and interpretation of data, and in writing, reviewing, and approving the publication. Anagha Vaidya is a former employee of AbbVie and is currently employed by Teva Pharmaceuticals. Jian-Hwa Han, Daniel Bonilla, and Stephen Anderson are AbbVie employees and may own AbbVie stock/options.

\section{REFERENCES}

1. $<711>$ Dissolution. In The United States Pharmacopeia and National Formulary USP 37-NF 32; The United States Pharmacopeial Convention, Inc.: Rockville, MD, 2014.

2. The Use of Mechanical Calibration of Dissolution Apparatus 1 and 2-Current Good Manufacturing Practice (CGMP); Guidance for Industry; U.S.
Department of Health and Human Services, Food and Drug Administration, Center for Drug Evaluation and Research (CDER), U.S. Government Printing Office: Washington, DC, 2010.

3. Mechanical Qualification of Dissolution Apparatus 1 and 2; DPA-LOP.002; U.S. Department of Health and Human Services, Food and Drug Administration, Division of Pharmaceutical Analysis, U.S. Government Printing Office: Washington, DC, 2006.

4. Standard Practice for Qualification of Basket and Paddle Dissolution Apparatus; ASTM Standard E2503-07; ASTM International: West Conshohocken, PA, 2007. DOI: 10.1520/E2503-07.

5. Moore, T. W.; Long, M. A.; Kentrup, W. A.; Oates, M. D.; Kelley, C.; Sojkowski, S. P. Implementation Guidance for American Society for Testing and Materials (ASTM) E2503-07 "Standard Practice for Qualification of basket and Paddle Dissolution Apparatus." Open Drug Delivery J. 2010, 4 (2), 14-20. DOI: 10.2174/1874126601004020014.

6. Nithyanandan, P.; Hauck, W. W.; Munoz, J.; Deng, G.; Brown, W.; Manning, R. G.; Wahab, S. Dissolution Variability: Comparison of Commercial Dosage Forms with US Pharmacopeia Lot P Prednisone Reference Standard Tablets-A Technical Note. AAPS PharmSciTech 2008, 9 (1), 238-242. DOI: 10.1208/ s12249-008-9034-z.

7. Eaton, J.; Deng, G.; Hauck, W. W.; Brown, W.; Manning, R. G.; Wahab, S. Perturbation Study of Dissolution Apparatus Variables-A Design of Experiment Approach. Dissolution Technol. 2007, 14 (1), 20-26. DOI: 10.14227/DT140107P20.

8. Salt, A.; Glennon, J. Enhanced Mechanical Calibration of Dissolution Test Equipment. Dissolution Technol. 2011, 18 (2), 25-29. DOI: 10.14227/DT180211P25.

9. Yan, B.; Lu, X.; Lozano, R. Feasibility Study on Quantification of USP Dissolution Apparatus 1 and 2 Using the Enhanced Mechanical Calibration Procedure. Dissolution Technol. 2011, 18 (2), 17-23. DOI: 10.14227/DT180211P17.

10. Boda, K.; Crist, B. G. Proper Implementation of Enhanced Mechanical Calibration of Dissolution Apparatus 1 and 2; Agilent Technologies Publication Number 5990-9866EN: Santa Clara, CA, May 2012.

11. Dissolution Toolkit Procedures for Mechanical Calibration and Performance Verification Test Apparatus 1 and Apparatus 2, Version 2.0; United States Pharmacopeial Convention, Inc.: Rockville, MD, 2010.

12. Deng, G.; Ashley, A. J.; Brown, W. E.; Eaton, J. W.; Hauck, W. W.; Kikwai, L. C.; Liddell, M. R.; Manning, R. G.; Munoz, J. M.; Nithyanandan, P.; Glasgow, 
M. J.; Stippler, E.; Wahab, S. Z.; Williams, R. L. The USP Performance Verification Test, Part I: USP Lot $P$ Prednisone Tablets-Quality Attributes and Experimental Variables Contributing to Dissolution Variance. Pharm. Res. 2008, 25 (5), 1100-1109. DOI: 10.1007/s11095-007-9498-7.

13. Glasgow, M.; Dressman, S.; Brown, W.; Foster, T.; Schuber, S.; Manning, R. G.; Wahab, S. Z.; Williams, R. L.; Hauck, W. W. The USP Performance Verification Test, Part I: Collaboration Study of USP's Lot P Prednisone Tablets. Pharm. Res. 2008, 25 (5), 11101115. DOI: 10.1007/s11095-007-9482-2.
14. DeStefano, A. J.; Hauck, W. W.; Stippler, E. S.; Brown, W. E.; Li, C.; Huang, G. G.; Jones, B. J.; O’Hool, K.; Koch, W. F.; Williams, R. L. Establishing New Acceptance Limits for Dissolution Performance Verification of USPC Apparatus 1 and 2 Using USPC Prednisone Tablets Reference Standard. Pharm. Res. 2011, 28 (3), 505-516. DOI: 10.1007/s11095-010-0295-3.

15. Gao, Z.; Moore, T.; Smith, A. P.; Doub, W.; Westenberger, B.; Buhse, L. Gauge Repeatability and Reproducibility for Accessing Variability During Drug Testing: A Technical Note. AAPS PharmSciTech 2007, 8 (4), 11-15. DOI: 10.1208/pt0804082. 